\title{
Temperament and character inventory (TCI) personality profile of alcohol misuse patients with and without a co-occurring mood or anxiety disorder Kaloyan Stoichev*, Krasimir Ivanov, Maria Alexandrova and Rumen Stoychev
}

Address: Department of Psychiatry, Pleven Medical University, Pleven, Bulgaria

* Corresponding author

\author{
from International Society on Brain and Behaviour: 3rd International Congress on Brain and Behaviour \\ Thessaloniki, Greece. 28 November - 2 December 2007 \\ Published: 17 April 2008 \\ Annals of General Psychiatry 2008, 7(Suppl I):SI 10 doi:10.1 186/1744-859X-7-SI-SI I0
}

This abstract is available from: http://www.annals-general-psychiatry.com/content/7/SI/SI I0

(C) 2008 Stoichev et al.; licensee BioMed Central Ltd.

\section{Background}

Alcohol use disorders (AUDs) are among the leading public health problems nowadays. Very often they co-occur with other psychiatric disorders, especially mood and anxiety disorders.

Quite a few studies exist that explore personality characteristics in individuals with alcohol misuse and a cooccuring mental disorder.

Such studies are of primary importance if we are to test the hypothesis that certain genetically inherited personality traits are a common risk factor for AUD and various externalizing and internalizing mental disorders.

\section{Materials and methods}

We examined two statistically matched groups (20 patients in each) of AUD patients (ICD-10 diagnosis of alcohol abuse or dependence). The first group consisted of patients with a lifetime diagnosis of mood/and or anxiety disorder and the second group included AUD patients without comorbid disorders. Lifetime psychiatric history was assessed "Composite International Diagnostic Interview" ver. 2.1 /lifetime/.

All the participants filled in the "Temperament and Character Inventory" self-evaluation questionnaire [1]. Data were processed with Statgraphics ver. 8.0.

\section{Results}

Preliminary results (the study is still ongoing) show that patients with a co-occurring mood and/or anxiety disorder tend to score much higher on harm-avoidance and lower on self-directedness subscales.

Taken together, these results may be interpreted as a higher propensity to personality deviations in these patients, most likely from the so-called cluster " $\mathrm{C}$ " personality register [2].

\section{Conclusions}

Additional studies with larger sample sizes are needed to further investigate the complex interaction and causal relationships between mood and anxiety disorders and alcohol misuse.

\section{References}

I. Cloninger C. R., Svrakic D. M., Przybeck T. R.: A psychobiological model of temperament and character. Archives of General Psychiatry 1993, 50:975-990.

2. American Psychiatric Association: Diagnostic and Statistical Manual of Mental Disorders. 4-th Edition edition. Washington, DC. American Psychiatric Association; 1994. 